\title{
Regimes semióticos do pertencimento nas metrópoles contemporâneas
}

\author{
Semiotic regimes of belonging in contemporary \\ metropolises
}

Massimo Leone

Professor de Semiótica e Semiótica da Cultura no Departamento de Filosofia, Universidade de Turim, Itália. O seu trabalho se concentra sobre a semiótica da cultura e a semiótica da religião. O seu último livro é Annunciazioni: percorsi di semiotica della religione (Roma: Aracne, 2014). -

Resumo: $\mathrm{O}$ artigo propóe um quadro teórico fenomenológico e semiótico para a inteligibilidade do sentido do pertencimento, um dos conceitos mais fundamentais nas culturas e sociedades atuais. Depois de definir o pertencimento como uma enunciação espacial que traz 1) as fronteiras de um espaço de pertencimento; 2) a oposição consequente entre um ambiente de pertencimento e um de não-pertencimento, e 3) a relação entre, por um lado, o sujeito da enunciação, e, por outro lado, a oposiçáo / ambiente do pertencimento / versus / ambiente de não-pertencimento /, o artigo articula uma tipologia de "figuras de atravessamento", em que o pertencimento se manifesta através da dialética narrativa entre colocação e deslocação. No quadro teórico da fenomenologia e da semiótica tensiva, quatro macro-regimes de pertencimento são apontados: "alienação sedentária", "pertencimento nômade", "alienação nômade", e "pertencimento sedentário". Além disso, quatro caminhos semânticos dinamicamente representando a transição entre estes regimes são identificados: "exílio / invasáo", "cosmopolitismo / curiosidade", "aclimatação / tolerância", e "alienaçãa / suspeita". Na conclusão, o quadro teórico desenvolvido pelo artigo é proposto como instrumento para a análise das "retóricas do pertencimento" nas culturas e sociedades atuais.

Palavras-chave: Pertencimento; fenomenologia; semiótica.

Abstract: The article proposes a phenomenological and semiotic theoretical framework for the intelligibility of the meaning of belonging, one of the most fundamental concepts in present-day cultures and societies. After defining belonging as a spatial enunciation that brings about 1) the frontiers of a space of belonging; 2) the consequent opposition between an environment of belonging and one of non-belonging; and 3) the relation between, on the one hand, the subject of enunciation and, on the other hand, the opposition lenvironment of belonging/ versus lenvironment of non-belongingl, the article articulates a typology of "figures of crossing," in which belonging is manifested through the narrative dialectics between placement and displacement. In the theoretical framework of tensive phenomenology and semiotics, four macro-regimes of belonging are singled out: "sedentary estrangement," "nomadic belonging," "nomadic estrangement," and "sedentary belonging." Moreover, four semantic paths dynamically representing the transition between these regimes are identified: "exile/invasion," "cosmopolitanism/curiosity," "acclimation/tolerance," and "alienation/suspicion." In the conclusion, the theoretical framework developed by the article is proposed as instrument for the analysis of the "rhetorics of belonging" in present-day cultures and societies.

Keywords: Belonging; phenomenology; semiotics 
Este artigo é parte dum projeto mais amplo de pesquisa que tem como objetivo explorar, do ponto de vista semiótico, o conceito de "sentimento de pertencimento". Neste ensaio cumprirei essencialmente três operaçôes. A primeira será aquela de "estar sobre os ombros dum gigante", o gigante, neste caso, sendo Jurij M. Lotman. Lotman dedicou inúmeros estudos e reflexões sobre o tema da fronteira e dos mecanismos linguístico-semióticos que a animam (LEONE 2006a e 2007; veja-se também Velázquez 2009). É suficiente lembrar a famosa máxima do estudioso de Tartu, segundo a qual as fronteiras, e mais geralmente os limites, seriam "um dos principais mecanismos de individuação semiótica” (Lotman 2000, p. 131, minha trad.). Mesmo a literatura secundária sobre Lotman enfatiza amiúde a centralidade do conceito de fronteira na escola de semiótica de Moscou / Tartu. Andrews e Maximova, por exemplo, escrevem que, de acordo com Lotman, a fronteira seria o mecanismo principal da semiose e que nisso as fronteiras seriam definidas como "multiplicidades de filtros bilíngues e membranas internos e externos que facilitam a permeabilidade e a fluidez e aceleram os processos semióticos" (Andrews-Maximova 2008, p. 260).

O segundo passo será aquele de revirar a perspectiva de Lotman sobre a fronteira, não porque ela seja insatisfatória mas bem porque não permite compreender plenamente a natureza dalguns fenômenos intimamente relacionados com a semiótica do sentido de pertencimento. Esta operação de reviramento consiste em explorar as fronteiras náo só do ponto de vista de sua estrutura imanente - ou seja, considerando-as como mecanismos ou dinâmicas semióticos que regulam a relação entre duas diferentes áreas culturais — mas também do ponto de vista fenomenológico do atravessamento delas - analisando-as, isto é, como propriedades semióticas dum contexto sociocultural que emergem duma instância de enunciação, ou melhor, do cruzamento de mais instâncias enunciativas.

Para este fim — e esta é a terceira operação — vou enriquecer a bagagem conceptual e analítica da semiótica da fronteira com referência tanto à semiótica greimasiana - e em particular à semiótica fenomenológica e tensiva do espaço de enunciação - quanto aos chamados "boundary studies", por exemplo, aos trabalhos de Hernes (2004), Tilly (2004), Bail (2008), Jones (2009) e outros estudiosos, especialmente ativos no âmbito da geografia humana.

Estou bem ciente de que a transição duma semiótica da fronteira a uma do atravessamento não é epistemologicamente indolor. Ela envolve uma mudança no baricentro teórico da estrutura inter-subjetiva da fronteira sociocultural à experiência subjetiva que a interação com esta estrutura provoca no atravessamento. O risco de psicologismo é alto. Para evitar isso, tentarei manter-me ao interior duma grade tipológica, seguindo nisto a lição do grande Lotman.

\section{Relações de pertencimento e enunciações espaciais}

O presente artigo pretende explorar as dinâmicas semióticas por meio das quais uma relação de pertencimento é estabelecida entre um sujeito (individual ou coletivo) e um espaço (físico ou conceitual, 'real' ou 'virtual'). 
Do ponto de vista semiótico, a origem fenomenológica de qualquer relação de pertencimento pode ser caracterizada como uma operação de enunciação espacial (sobre a gênese do concepto de enunciação, Benveniste 1966 e 1971; para una resenha da teoria de Benveniste sobre enunciação, Ono 2007; para una síntese eficaz desta tradição de estudos, Manetti 1998 e 2008; para uma interessante abordagem fenomenológica à semiótica da enunciação, Coquet 2007; a literatura sobre o estudo semiótico e linguístico do espaço é igualmente copiosa. Entre os contributos mais recentes, Cavicchioli 1997; Hess-Lüttich, Müller, e Van Zoest 1998; Cavicchioli 2002; Hammad 2006; Schönle 2006; Lussault 2007 (e as outras obras deste "geografo semiótico"); Marcos 2007; Auer e Schmidt 2010 (especialmente o cap. 1); Jaworski e Thurlow 2010).

Através desta operação, três elementos são enunciados ao mesmo tempo: 1) as fronteiras duma zona de pertencimento, que podem ser mais ou menos pronunciadas; 2) a oposição consequente entre um ambiente de pertencimento e um de não pertencimento; 3) e a relação entre, por um lado, o sujeito da enunciação e, por outro, a oposição / ambiente de pertencimento / versus / ambiente de não pertencimento \% A pesar de que estes três elementos podem ser separados teoricamente, eles são, do ponto de vista fenomenológico, inextricáveis: uma relação de pertencimento não pode existir sem a oposição entre um ambiente de pertencimento e um de não pertencimento; esta oposição não pode existir sem a enunciação das fronteiras dum espaço de pertencimento, e assim por diante.

A relação de pertencimento entre um cidadão e um bairro, por exemplo, não é determinada apenas pela burocracia administrativa (Mohr 2009). Para finalidades administrativas, a burocracia pode estabelecer que um cidadáo pertence a um determinado bairro, a pesar do cidadão não sentir que pertence a esse lugar em particular mas à algum outro lugar, por exemplo ao bairro de sua infância. Pelo contrário, esta relação de pertencimento é estabelecida por meio duma enunciação espacial que:

- projeta sobre a mapa da cidade as fronteiras dum espaço de pertencimento (Leone 2010a). Elas podem ser mais ou menos pronunciadas: para alguns cidadãos, seu bairro será definido por certas vias específicas, enquanto para outros ele será delineado não por fronteiras limpas mas bem por limiares mais matizados, por exemplo, um grupo de vias, ou mesmo um grupo de blocos (LEONE 2009a e 2011b);

- produz uma oposição entre um ambiente de pertencimento e um de não pertencimento. Mais uma vez, tal oposição pode ser mais ou menos acentuada, dependendo de quanto serem nítidas as fronteiras do espaço de pertencimento. Em alguns casos, até mesmo atravessar uma soa rua dissipará o sentimento de pertencimento dum cidadão, enquanto em alguns outros casos, o cidadão terá que andar a pé ou de carro através de toda uma série de estradas antes de perceber que, gradualmente, entrou em uma área da cidade à que não pertence (Leone 2010b);

- estabelece uma relação entre o cidadão e a oposição / ambiente de pertencimento / versus / ambiente de não pertencimento /. Em outras palavras, 
transforma a relação entre o cidadão e o espaço urbano numa relação modulada, consistindo de oposiçôes cognitivas, pragmáticas e emocionais. Em determinadas áreas da cidade — aqueles as quais pertence — o cidadáo terá a impressão de conhecer o ambiente, de ser capaz de agir nele e por ele, e de sentir-se à vontade: estas são as características básicas dum ambiente urbano de pertencimento. Fora destas áreas, no entanto, onde ele não pertence, o cidadão vai ter a impressão de náo conhecer o ambiente, de ser incapaz de agir nele e por ele, e de não sentir-se à vontade: estas são as características básicas dum ambiente urbano de não pertencimento (Leone 2010b).

\section{A dialética entre colocação e deslocação}

Tendo em conta que uma certa relação de pertencimento é estabelecida através duma enunciação que estabelece uma ligação entre um sujeito e um espaço modulado por fronteiras, esta relação pode ser revelada somente por meio da dialética entre colocação e deslocação. Por "colocação" aqui se quer designar a operação por meio da qual uma relação de pertencimento é estabelecida através da enunciação duma ligação entre um sujeito e um espaço modulado por fronteiras. Pelo contrário, a deslocação é a operaçáo por meio da qual esta relação se dissolve.

A fenomenologia e a semiótica têm que investigar os processos pelos quais tais fronteiras são enunciadas na relação entre um sujeito e um espaço: porque as fronteiras são enunciadas duma certa maneira, produzindo uma certa série de modulaçóes opositivas? A criação de tais modulações depende talvez exclusivamente do sujeito da enunciação, das características materiais do espaço, ou duma combinação de ambos? E como é possível caracterizar essa combinação?

O presente artigo tem como objetivo explorar uma questão fenomenológica e semiótica preliminar: de que maneira a existência dum ambiente de pertencimento é revelada aos sujeitos em primeiro lugar? De que maneira os sujeitos percebem que há certos espaços físicos e conceituais aos que pertencem e outros aos que não pertencem? A hipótese principal deste artigo é que os sujeitos (individuais e coletivos) não tomam conhecimento da existência dum ambiente de pertencimento quando contribuem para sua enunciação. Em vez disso, eles tornam-se conscientes deste ambiente quando experimentam a oposição entre tal ambiente de pertencimento e um ambiente oposto de não pertencimento. Esta oposição não pode ser vivida em abstrato mas, como já foi dito acima, só pode ser sentida através da dialética entre colocação e deslocação, ou seja, quando seja vivida como uma transição (CRAPANZANO 2003).

É na transição entre um ambiente de pertencimento e um de não pertencimento que os sujeitos são capazes de interagir com as modulações opositivas criadas pela projeção de fronteiras sobre um determinado espaço. Por exemplo, um cidadão não percebe que ele pertence a um determinado bairro em términos abstratos e absolutos, mas como resultado duma transição infeliz, quando o atravessamento duma rua, dum parque ou duma praça, dá lugar à transição entre um ambiente de pertencimento e um de não pertencimento, isto é, na experiência das fronteiras. 
Portanto, antes de qualquer consideração sobre a construção dessas fronteiras, este artigo se focalizará principalmente sobre as dinâmicas através das quais essas fronteiras são percebidas. Como será evidente, a detecção transicional das fronteiras e sua enunciação podem ser separadas apenas teoricamente, dado que elas são parte da mesma dinâmica fenomenológica e semiótica. No entanto, seguindo uma abordagem fenomenológica mais que construtivista, este artigo irá examinar primeiro os processos semióticos por meio dos quais as fronteiras são colhidas, deixando para um momento posterior a tarefa de reconstruir a fenomenologia de sua enunciação.

\section{Figuras do atravessamento: intensidade e extensão da transição}

Para esta finalidade, o presente artigo irá analisar uma série de figuras do atravessamento, isto é, modelos narrativos através dos quais a transição entre colocação e deslocação, entre um ambiente de pertencimento e um de não pertencimento, é imaginada nas sociedades e nas culturas contemporâneas.

Dois fatores desempenham um papel chave na determinação da semântica destas figuras de atravessamento: por um lado, elas podem ser classificadas de acordo com a intensidade de transição entre ambientes de pertencimento e ambientes de não pertencimento, intensidade que estas figuras manifestam em termos narrativos. Por outro lado, elas podem ser classificadas de acordo com a extensão de distância entre ambientes de pertencimento e ambientes de não pertencimento, extensão que estas figuras também revelam através de formas narrativas. $\mathrm{O}$ par de conceitos intensidade de transição / extensão de distancia procura capturar a fenomenologia do atravessamento duma fronteira e, assim, a dialética entre locação e deslocação, a partir do ponto de vista duplo oferecido pela concepção estrutural, e especialmente greimasiana, do espaço: a extensão de distancia colhe a fenomenologia do atravessamento do ponto de vista do espaço concebido como étendue, como uma extensão, isto é; a intensidade de transição, pelo contrario, colhe a mesma fenomenologia do ponto de vista do espaço concebido como forma, como modulação semântica de tal extensão.

O sentimento de pertencimento é inversamente proporcional à intensidade de transição (mais aguda é a percepção do atravessamento duma fronteira entre ambientes de pertencimento e de não pertencimento, menos intenso será o sentimento de pertencimento após tal atravessamento). De modo semelhante, o sentimento de colocaçáo é inversamente proporcional à extensão de distância (mais importante é o movimento implicado pelo atravessamento duma fronteira entre ambientes de pertencimento e não pertencimento, e menos intenso será o sentimento de colocação após o atravessamento).

No que respeita à intensidade de transição, as figuras de atravessamento podem ser situadas ao longo dum continuo: numa extremidade, vamos encontrar figuras de atravessamento que manifestam, em termos narrativos, aquelas passagens nas quais o diferencial semântico entre um ambiente de pertencimento e um de não pertencimento é mínimo. Noutro extremo, ao contrário, vamos encontrar figuras de atravessamento que manifestam, em termos narrativos, as transiçóes nas quais o diferencial entre um ambiente de pertencimento e um de não pertencimento é máximo. Os níveis mínimo e máximo aqui não 
devem ser considerados em termos absolutos, mas relativos, como polaridades no campo semântico do pertencimento que caracterizam uma determinada sociedade e sua cultura.

Por exemplo, enquanto em muitas cidades ocidentais uma viagem em carro fora da cidade, primeiro através dos subúrbios e após na zona rural circundante, normalmente não se considera como uma transição dramática, na maioria das sociedades e das culturas antigas e medievais o atravessamento dos portôes da cidade foi frequentemente caracterizado por uma transição dramática dum ambiente de pertencimento a um de não pertencimento. $\mathrm{O}$ espaço entre os dois diferenciais semânticos de pertencimento, mínimo no primeiro caso, e máximo no segundo, depende das diferentes formas em que as fronteiras do pertencimento são enunciadas nos dois contextos históricos e culturais: no primeiro caso, apenas sinais burocráticos dizem ao motorista que, por exemplo, está localizado fora da cidade de Turim e está, portanto, caminhando para terra incógnita; no segundo caso, muralhas imponentes, portais, e soldados inquisidores marcam a transição da cidade pelo espaço circundante.

No entanto, os textos narrativos podem jogar com estes diferenciais. Por exemplo, eles podem representar uma simples viagem de carro fora da cidade como uma figura de atravessamento dramática, a fim de enfatizar a oposiçáo semântica entre o centro e a periferia: a passagem da primeira pela segunda, portanto, implica uma transição entre um ambiente de pertencimento e um de não pertencimento tão clara como o sair duma cidade fortificada em tempos medievais. Por outro lado, um diferencial semântico de pertencimento pode ser amesquinhado por uma narrativa que minimiza a experiência do atravessamento das muralhas duma cidade fortificada, e a transição entre ambientes de pertencimento e náo pertencimento que tal atravessamento envolve (cada espécie de paródia frequentemente usa esta estratégia narrativa).

As figuras de atravessamento podem ser situadas ao longo dum continuo, não só com respeito a nitidez da transição entre pertencimento e não pertencimento que elas manifestam em termos narrativos, mas também respeito à dialética entre colocação e deslocação, que elas também revelam por meio de formas narrativas. Numa extremidade do continuo encontraremos figuras de atravessamento em que tal dialética atinge níveis máximos, nomeadamente, figuras de atravessamento nas quais a distância física ou conceptual entre um espaço de pertencimento e um de não pertencimento é máxima. Noutra extremidade, no entanto, vamos encontrar figuras de atravessamento em que esta distância é mínima.

Mais uma vez, a tensão entre as figuras de atravessamento que envolvem uma experiência dramática da distância e aquelas em que esta experiência é mínima não deve ser entendida em termos absolutos mas relativos, isto é, no contexto do campo semântico do pertencimento que caracteriza uma dada sociedade e sua cultura. Voltando ao exemplo dado anteriormente, nas cidades Católicas pré-modernas o campanário foi um landmark e um soundmark fundamental de pertencimento: não ser capaz de vê-lo, ou pior ainda, ouvir seus sinos, eram ambos sinais de distância intolerável do ambiente de pertencimento 
que à cidade e sua igreja asseguravam (LEONE 2012).

Nas sociedades pós-modernas e pós-católicas, entanto, formas muito mais dramáticas de deslocação são necessárias para garantir que os cidadãos façam a experiência da transição entre um ambiente de pertencimento e um de não pertencimento. Só depois de viagens longas e caras, por exemplo, e só depois de ter ouvido que o tilintar dos sinos foi substituído pela voz do muezim, o cidadão contemporâneo, pós-moderno e pós-católico, percebe que, na verdade, os sinos fazem parte da sua "paisagem sonora" de pertencimento.

Neste caso também, os textos narrativos podem jogar com as polaridades da colocaçáo e da deslocação e com os sentimentos de distancia e de pertencimento que elas implicam. As narrativas pós-modernas podem representar o simples fato de pôr o pé fora de seu quarto como uma espécie de êxodo, em que o movimento através duma distância muito pequena implica a experiência duma transição dramática entre um ambiente de pertencimento e um de não pertencimento. Pelo contrário, as paródias ou outros géneros similares podem representar até o êxodo bíblico — isto é, a deslocação por antonomásia da cultura "ocidental" - como um movimento em que a longa distância coberta não está associada com um sentimento igualmente impressionante da transição dum ambiente de pertencimento a um de não pertencimento.

Em resumo, enquanto o primeiro fator mede a nitidez da transição entre pertencimento e não pertencimento que esta figura manifesta em termos narrativos (intensidade de transição), o segundo fator mede quão dramática é a distância entre colocação e deslocação que uma certa figura de atravessamento revela por meio de formas narrativas (extensão de distância). Enquanto que a intensidade da transição mede o diferencial semântico produzido pelo atravessamento duma fronteira, a extensão de distancia mede o diferencial sintático necessário para o atravessamento duma fronteira ser produzido. Obviamente, estes dois aspectos são indissociáveis na experiência, e podem ser distinguidos apenas na teoria.

\section{As polaridades do pertencimento}

A matriz de possibilidades semióticas que resulta da combinação destes dois fatores pode ser visualizada por meio dum diagrama tensivo (Fig. 1) (Fontanille e Zilberberg 1998 e Zilberberg 2006):

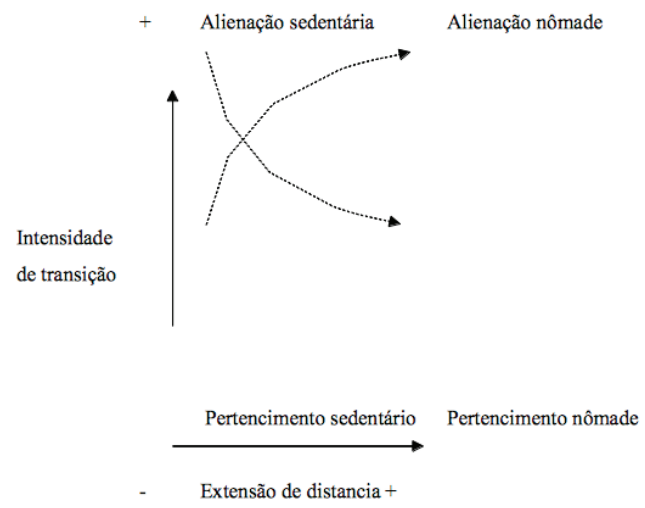

Fig. 1 - O diagrama tensivo dos regimes de pertencimento. 
Quatro áreas podem ser identificadas neste diagrama. Elas foram lexicalizadas como "pertencimento sedentário", "alienação sedentária”, "pertencimento nômade", e "alienação nômade". Como acontece sempre nos diagramas tensivos, o que importa náo são as lexicalizaçóes mas a combinação de traços semânticos que as subtendem.

$\mathrm{Na}$ parte esquerda do diagrama, encontramos figuras de atravessamento caracterizadas por deslocação mínima, ou seja, extensão mínima de distância. Combinado com o fator do pertencimento (ou seja, a intensidade de transição), esta deslocação mínima dá origem a duas áreas semânticas: "pertencimento sedentário" e "alienação sedentária”. As figuras de atravessamento em ambas as áreas são caracterizadas por seu manifestar, em termos narrativos, transiçóes entre um ambiente de pertencimento e um de não pertencimento que envolvem distância mínima (claro, sempre dentro duma determinada sociedade e de sua cultura). No entanto, enquanto as figuras de atravessamento da primeira área ("pertencimento sedentário") têm pouco efeito quanto para revelar a dialética entre colocação e deslocação e entre ambientes de pertencimento e ambientes de não pertencimento, as figuras da segunda área ("alienação sedentária” ) combinam uma extensão de deslocação mínima com a plena consciência das fronteiras.

Alguns exemplos esclarecerão o sentido destas duas primeiras categorias de figuras de atravessamento. A área no canto inferior esquerdo ("pertencimento sedentário") contém figuras que expressam por meio de formas narrativas a ideia de que quando um sujeito (seja ele um indivíduo ou um grupo) se move através duma fronteira de algum tipo, não experimenta nem a distância de deslocação nem a intensidade de transição entre um ambiente de pertencimento e um de não pertencimento. As rotinas são frequentemente figuras de atravessamento que se enquadram nesta categoria (Leone 2011a). Elas são formas narrativas que transmitem a ideia de que a fronteira entre um ambiente de pertencimento e um de não pertencimento, bem como a distância entre eles, é cancelada.

A transição entre a vigília e o sono, por exemplo, poderia ser vivida como uma das mais dramáticas da vida diária (Caillois 1956). A passagem, pelo limiar do adormecer-se, entre o ambiente da consciência ao ambiente da sua ausência poderia lembrar uma das transiçóes mais dramáticas da existência humana, aquela entre o reino do pertencimento relativo, ou seja a vida, e o reino do náo pertencimento absoluto, ou seja a morte. Alguns são tão aterrorizados por esta transição que, mais ou menos conscientemente, se recusam a vivê-la. A partir deste ponto de vista, a insônia é nada mais do que a recusa de experimentar a transição pelo não pertencimento da falta de consciência e da morte.

Em contraste, muitos “domam” esta transição por meio de rotinas: 
açóes e palavras feitos todos os dias antes de ir dormir, por exemplo colocar um copo de água na mesa-de-cabeceira ou fazer alguma conversa ritual com o seu parceiro, constroem uma narrativa diária em que a fronteira entre vigília-vida e sono-morte, bem como a distância entre estes domínios, é cancelada.

Da mesma forma, a área no canto superior esquerdo ("alienação sedentária”) contém figuras que expressam, por meio de formas narrativas, a ideia de que, quando um sujeito (seja ele um indivíduo ou um grupo) se move através duma fronteira dalgum tipo, não experimenta a distância de deslocação entre um ambiente de pertencimento e um de não pertencimento, mas percebe, no entanto, a intensidade de transição entre eles. Como mostrei em outro estudo, quando as rotinas deixam de fornecer formas narrativas para a domesticação da experiência do não pertencimento, elas dão origem a figuras de atravessamento que muitas vezes caem na categoria de "alienação sedentária".

Por exemplo, a pequena transição entre a própria casa e a estrada poderia ser vivida — analogamente à transição entre a vigília e o sono - como uma transição dramática entre um ambiente de pertencimento e um de não pertencimento, do reino da vida segura e da certeza para o reino da incerteza e da morte potencial. Também neste caso, por meio de mecanismos narrativos que analisei em outro estudo, as rotinas normalmente protegem as pessoas contra a consciência de tal transição. A repetição de palavras e gestos "no limite", por exemplo garantir que as luzes sejam desligadas ou observar-se no espelho, quebram o sentimento da intensidade desta transição.

No entanto, como o poder de "anestesia" destes rotinas falhe (Leone 2003), a consciência da existência duma fronteira nítida emerge apesar da modéstia da distância implicada. Para algumas pessoas, colocar o pé fora da porta da casa pode se tornar táo intolerável quanto o fato de ir dormir para alguns outros. A partir deste ponto de vista, a agorafobia manifesta em termos espaciais o que a insônia revela em termos temporais: o fracasso das rotinas em sua qualidade de figuras narrativas de atravessamento capazes de "mascarar" a existência duma fronteira entre um ambiente de pertencimento e um de náo pertencimento.

$\mathrm{Na}$ parte direita do diagrama semiótico tensivo encontraremos duas categorias de figuras de atravessamento, ambas caracterizadas por altos níveis de deslocação, ou seja, por níveis (relativamente) altos da extensão de distancia implicada pelo movimento através duma fronteira. No entanto, estas categorias são diferentes com respeito ao nível de intensidade de transição. A área no canto inferior direito, em particular, classifica as figuras de atravessamento denominadas "pertencimento nômade". As modulaçôes narrativas nesta área são semanticamente opostas às da área 
chamada "alienação sedentária". Neste caso, apesar da importância da distância implicada por um movimento através duma fronteira entre um ambiente de pertencimento e um de não pertencimento, as modulaçôes narrativas podem narcotizar a sensação desta passagem. Os textos que representam a atitude cosmopolita dos que acreditam que "o mundo é sua casa", que eles são "cidadãos do mundo", que "o mundo não tem fronteiras ou nacionalidade", e que, por isso, eles "pertencem a todos os lugares", exemplifica perfeitamente as figuras de atravessamento categorizadas na área do "pertencimento nômade" Nesta área, a experiência das fronteiras desaparece, deixando apenas aquela do movimento (Beck 2004; Appiah 2006; Sassen 2007; Benhabib 2008; Delanty 2009; Harvey 2009; Holton 2009; Kendall, Woodward, e Skrbis 2009; Cabrera 2010; Chung e Nootens 2010; Forte 2010; Mau 2010; Delanty e Inglis 2011).

Esta categoria de figuras de atravessamento manifesta, por meio de formas narrativas, não só a mentalidade pós-moderna dos cosmopolitas, mas também a atitude pré-moderna dos nômades. No entanto, e vamos a aprofundá-lo mais diante, o textos nômades não transmitem simplesmente a ideia do desaparecimento das fronteiras, mas bem o conceito de que a modulação sedentária das fronteiras é substituída por uma nômade, em que a intensidade da transição através da maioria das fronteiras é amesquinhada e, por vezes, aniquilada (Scholz 1995; Attali 2003; Leder e Streck 2005; Callari Galli 2007; Ó hAodha 2007; Barnard e Wendrich 2008; Nascimento 2008).

A área no canto superior direito do diagrama tensivo contém figuras de atravessamento que revelam, por meio de formas narrativas, uma fenomenologia das fronteiras que é semanticamente oposta à chamada "alienação sedentária". Nesta área, chamada de "estranhamento nômade", vamos encontrar figuras de atravessamento caracterizadas por alta intensidade de transição e ao mesmo tempo elevada extensão de distância. Representaçôes do exílio de qualquer tipo são típicas desta área. Mais geralmente, se enquadram nesta categoria todas as figuras "épicas" de atravessamento, onde a grande distância coberta para se deslocar dum ambiente de pertencimento a um de não pertencimento é acompanhada por uma experiência dramática da fronteira entre os dois (Ouditt 2002; Allatson e McCormack 2008; Carrera 2010; Genova e Peutz 2010).

\section{Percursos entre regimes de pertencimento}

O diagrama semiótico tensivo construído e descrito até agora tem de ser considerado não apenas como uma representação visual estática das diferentes categorias de figuras de atravessamento, mas também como sua visualização dinâmica. O diagrama mostra a possibilidade de diferentes percursos semânticos entre as quatro categorias de atravessamento só agora identificadas. Quatro deles são particularmente interessantes, pois representam transformaçóes entre polaridades semânticas opostas. As primeiras dois são representadas no diagrama semiótico 
tensivo da figura 2:

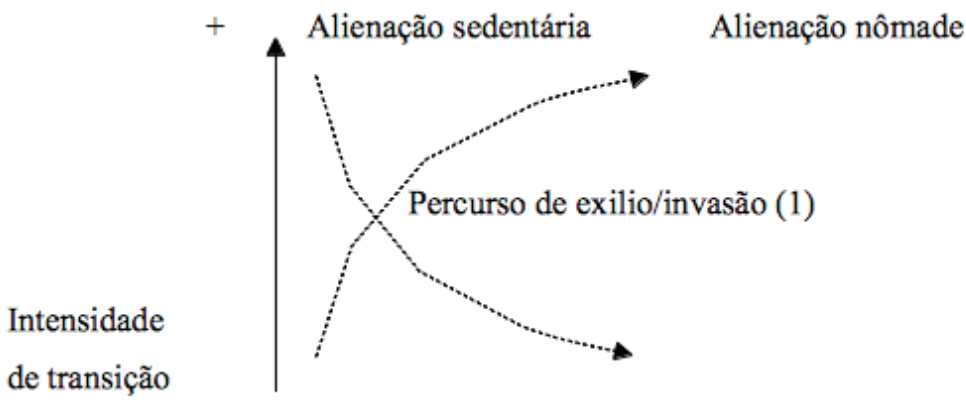

Percurso de cosmopolitismo/curiosidade (2)

Pertencimento sedentário

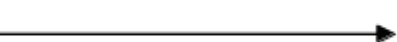

Extensão de distancia +

Fig. 2 - O diagrama tensivo dos percursos de pertencimento, parte 1.

O primeiro percurso, chamado "exílio / invasão", está na base das narrativas textuais em que a experiência dum sujeito (individual ou coletivo) ocorre substituindo gradualmente as figuras de pertencimento sedentário com aquelas de alienação nômade. Dada a lógica que está por trás do diagrama acima, as implicações fenomenológicas desta substituição deveriam ser bastante claras: figuras de atravessamento caracterizadas por intensidade de transição e extensão de distancia mínimas se tornam cada vez mais substituídas por figuras de atravessamento que implicam intensidade de transição e extensão de distância máximas. O percurso de exílio, portanto, resume os traços semânticos daquelas modulações narrativas que evocam uma passagem dramática entre dois "regimes de pertencimento", aquele em que a experiência das fronteiras é amesquinhada em relação a ambas a sua intensidade e a sua extensão, e aquele em que tal experiência é aumentada em ambos os sentidos.

Todas as narrativas de exílio, migração e erradicação podem ser interpretadas, por exemplo, como narrativas que manifestam, por meio de formas narrativas, esse percurso semântico. O percurso de exílio / invasáo subjaz às narrativas textuais de sujeitos cuja extensa deslocação através do espaço (físico ou conceitual, "real" ou virtual) coincide com uma intensa experiência de não pertencimento, de atravessamento das fronteiras entre um ambiente de pertencimento e um de não pertencimento (Leone 2010c).

No entanto, este percurso semântico, bem como aqueles que serão discutidos mais tarde, estão de base não só aos textos em que a transição entre regimes de 
pertencimento diferentes é representada do ponto de vista do sujeito dinâmico isto é, aquele (seja ele um indivíduo ou um grupo) que se move no espaço e atravessa fronteiras —, mas também do ponto de vista do sujeito estático, ou seja, aquele que, enraizado num ambiente de pertencimento, vê as fronteiras dele atravessadas por alguém ou algo que vem de fora. As transiçôes entre os regimes de pertencimento que incorporam um percurso semântico de exilio a partir da perspectiva do sujeito dinâmico, manifestam um percurso de invasão a partir do ponto de vista do sujeito estático.

Como veremos mais em detalhes adiante, neste primeiro percurso semântico o sujeito estático e o dinâmico são também um o anti-sujeito doutro: o primeiro está preocupado que o exílio do segundo causará sua própria invasão e portanto exílio, e o desmantelamento de seu próprio regime de pertencimento sedentário (Leone 2010b). O sujeito dinâmico, ao contrário, poderia ver seu próprio regime de alienação nômade como consequência do agarramento antagônico do sujeito estático para seu próprio regime de pertencimento sedentário. Em outras palavras, como o atravessamento da fronteira pelo sujeito dinâmico em exílio de repente torna-a dramaticamente perceptível pelo sujeito estático, assim o entrincheiramento com o qual o sujeito estático protege esta fronteira da "invasão" do sujeito dinâmico torna-a mais visível pelo segundo. As narrativas de pertencimento não são nada mais que a manifestação textual da dialética entre sujeito estático e sujeito dinâmico, a qual, por sua vez, nada mais é que a manifestação antropomórfica da batalha de regimes semânticos de pertencimento que eles encarnam.

O segundo percurso, chamado "percurso de cosmopolitismo / curiosidade", subtende essas narrativas textuais subjacentes em que a experiência dum sujeito (individual ou coletivo) manifesta-se pela substituição progressiva de figuras de alienação sedentária com aquelas de pertencimento nômade. Do ponto de vista fenomenológico, esta substituição implica que as figuras de atravessamento caracterizadas por máxima intensidade de transição e mínima extensão de distancia gradualmente dão lugar a aquelas que envolvem máxima extensão de distância e mínima intensidade de transição. O percurso de cosmopolitismo / curiosidade, portanto, resume as características semânticas das modulaçóes narrativas que evocam uma passagem dramática entre dois "regimes de pertencimento": um no qual a experiência das fronteiras é amesquinhada em extensão e ampliada em intensidade, e outro no qual a experiência é ampliada em extensão e amesquinhada em intensidade. Por exemplo, as narrativas em que um sujeito "com medo do mundo" de alguma forma encontra a força para fazer uma viagem e descobre que o mundo pode se tornar "a sua casa", podem ser interpretadas de modo a manifestar, em formas narrativas, este percurso semântico.

Exatamente como o primeiro percurso semântico, também aquele de cosmopolitismo / curiosidade subtende não só narrativas do ponto de vista do sujeito dinâmico (o que atravessa as fronteiras), mas também a partir do ponto de vista do sujeito estático (o que vê as fronteiras atravessadas pelo sujeito dinâmico). Neste percurso semântico (o que chamaremos "percurso semântico de curiosidade") um 
sujeito estático (seja ele um indivíduo ou um grupo) muda de ficar chocado ou mesmo horrorizado com as diferenças que vêm doutros lugares para ser neutro ou mesmo curioso e entusiasmado com elas. É o percurso semântico típico dos que, inicialmente chocados com a diferença que vem doutro lugar, gradualmente vê-la transformar-se num elemento constitutivo de seu "aqui", de seu ambiente de pertencimento.

$\mathrm{Na}$ verdade, o percurso semântico que vai desde a alienação sedentária ao pertencimento nômade envolve não só o fato de atravessar as fronteiras do mundo sem percebe-las, mas também o fato de deixar que os outros façam o mesmo sem senti-lo. Em outras palavras, os textos "curiosos" expressam a ideia de que quando eu, sujeito estático, me depare com alguém ou alguma coisa que provem doutro lugar distante, não interprete esta reuniáo como o resultado dum atravessamento da fronteira entre o seu ambiente de pertencimento e o meu (isto é, o seu ambiente de não pertencimento), mas como resultado do nosso mover-nos em um ambiente de pertencimento comum, no qual a intensidade da transição das fronteiras é constantemente reduzida (Leone 2006b).

Enquanto nas "narrativas cosmopolitas" a intensidade da transição é sistematicamente narcotizada quando o sujeito dinâmico atravesse as fronteiras do mundo, nas "narrativas curiosas" a intensidade da transição é sistematicamente diminuída quando o sujeito estático vê o dinâmico atravessar as fronteiras do mundo. O resultado desta atenuação sistemática da intensidade de transição envolvida no atravessamento de fronteiras é que o sujeito estático e o dinâmico não podem ser mais um o anti-sujeito doutro, como acontecia nas narraçôes de exílio e invasão. Pelo contrário, neste caso, as posiçôes fenomenológicas e semióticas daquele que convida e daquele que é convidado se confundem, a ponto de o cosmopolitismo do sujeito dinâmico alimentar a curiosidade do estático e vice-versa.

O terceiro e o quarto "percursos de pertencimento" são representados visualmente no diagrama da Figura 3.
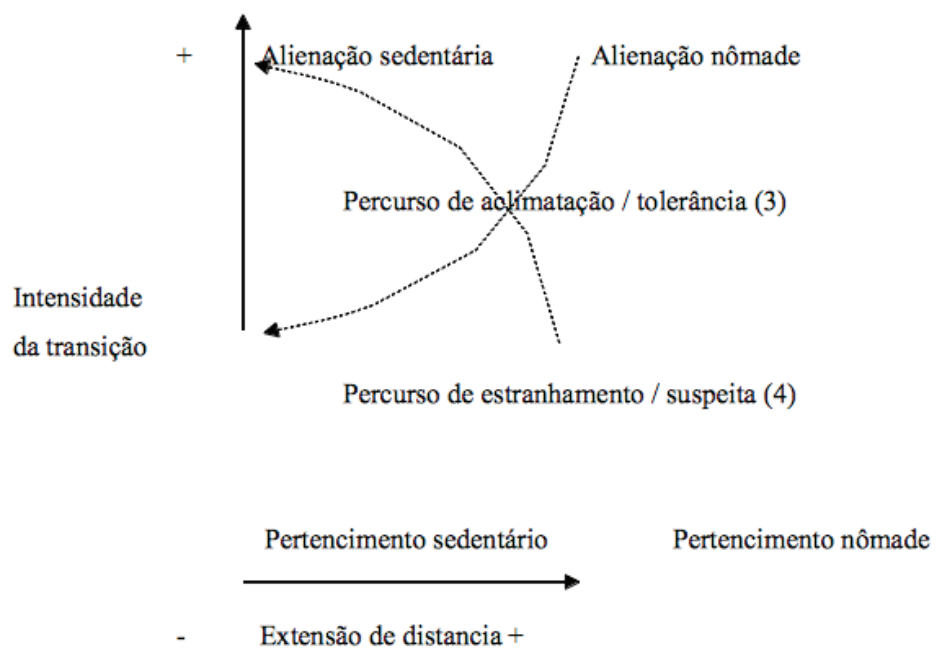

Fig. 3 - O diagrama tensivo dos percursos de pertencimento, parte 2. 
O terceiro percurso, chamado "percurso de aclimatação / tolerância", está na base das narrativas textuais em que a experiência do sujeito (individual ou coletivo) se manifesta pela substituição gradual de figuras de alienação nômada com as de pertencimento sedentário. Do ponto de vista fenomenológico, tal substituição implica que as figuras de atravessamento caracterizadas por intensidade de transição e extensão de distancia máximas gradualmente dão lugar a figuras que envolvam extensão de distância e intensidade de transição mínimas. O percurso de aclimatação / tolerância, portanto, resume as características semânticas dessas modulaçôes narrativas que evocam uma passagem dramática entre dois "regimes de pertencimento": um no qual a experiência das fronteiras é ampliada em ambas extensão e intensidade, e outro no qual, pelo contrário, tal experiência é diminuída em relação tanto à extensão quanto à intensidade.

Este percurso semântico subtende, por exemplo, as narrativas de “integração cultural", em que um sujeito dinâmico torna-se progressivamente o sujeito estático dum novo ambiente de pertencimento. A transição entre a experiência das fronteiras dos migrantes de primeira e segunda geração ocorre frequentemente por meio de textos narrativos caracterizados por um percurso semântico de aclimatação: a intensidade da transição e a extensão da distância, implicadas pela chegada e pela presença de migrantes de primeira geração num novo ambiente de pertencimento são gradualmente amesquinhadas pela permanência dos imigrantes de segunda geração no mesmo ambiente. Pelos imigrantes de segunda geração, o mesmo ambiente se torna seu ambiente de pertencimento a tal ponto que às vezes eles podem agir como um "sujeito estático" contra outros migrantes de primeira geraçáo e, portanto, considerá-los como “invasores" (de acordo com a lógica apresentada pelo primeiro diagrama tensivo).

O que do ponto de vista do sujeito dinâmico é o percurso semântico de aclimatação, do ponto de vista do sujeito estático é o percurso semântico de tolerância: nas modulações narrativas subtendidas por este percurso, os iniciados gradualmente aprendem a ver os estranhos como pertencentes a seu próprio ambiente e, portanto, a esquecer a fronteira entre "nós" e "eles". Tal como no percurso semântico de cosmopolitismo / curiosidade, também aqui a relação entre o sujeito dinâmico e o sujeito estático é não-antagonista, visto que em ambos casos, a intensidade da transição é diminuída.

No entanto, o percurso semântico de cosmopolitismo / curiosidade difere do de aclimatização / tolerância no que se refere à extensão de distância: embora no cosmopolitismo e na curiosidade o sujeito estático e o dinâmico se consideram um ao outro como pertencendo ao mesmo ambiente, eles não esquecem a distância entre eles. Noutras palavras, no cosmopolitismo / na curiosidade o outsider pertence como outsider e náo como insider, dado que a diferença entre o interior e o exterior está desfocada.

$\mathrm{Na}$ aclimatação e na tolerância, ao contrário, o sujeito estático e o dinâmico se consideram mutuamente como pertencentes ao mesmo ambiente precisamente 
porque esquecem a distância que os separa. Noutras palavras, na aclimatação / tolerância, o intruso pertence apenas na medida em que se transforma num insider; não pertence como outsider, porque a diferença entre o interior e o exterior é mantida.

Finalmente, o quarto percurso, chamado de "alienação / suspeita", está na base das narrativas textuais em que a experiência dum sujeito (individual ou coletivo) se manifesta na substituição gradual das figuras de pertencimento nômade com as de estranhamento sedentário. Do ponto de vista fenomenológico, tal substituição implica que as figuras de atravessamento caracterizadas por mínima intensidade de transição e máxima extensão de distância são substituídas pelas figuras que implicam máxima intensidade de transição e mínima extensão de distância. $\mathrm{O}$ percurso de estranhamento / suspeita, portanto, resume as características semânticas das modulaçôes narrativas que evocam uma passagem dramática entre dois "regimes de pertencimento": um no qual a experiência das fronteiras é ampliada em extensão mas diminuiu de intensidade, e outro em que tal experiência é diminuída em extensão e aumentada em intensidade.

A experiência da pessoa que "não reconhece mais a sociedade em que ele/ela vive" é, por exemplo, uma concretização narrativa típica do percurso de estranhamento. Neste caso, o sujeito não vai se afastar em espaços remotos (tanto físicos quanto conceituais, "reais" ou virtuais) para perceber que não pertence; no entanto, este sentimento de não pertencimento surpreende o sujeito em sua própria casa, rodeado por seu ambiente, insider entre insiders.

O que, do ponto de vista do sujeito dinâmico é o percurso semântico de alienação, a partir da perspectiva do sujeito estático é o percurso semântico de suspeita. No entanto, tal como no percurso semântico de cosmopolitismo / curiosidade o papel do sujeito dinâmico e o do sujeito estático são confundidos como resultado do facto de que um alimenta a posição semântica doutro, assim as mesmas funçóes são misturadas no percurso semântico de alienação / suspeita: todos os sujeitos suspeitam que os outros sujeitos no mesmo ambiente em realidade não pertencem lá, mas ao fazê-lo alimentam uns o sentimento de não pertencimento doutros. Como no percurso semântico de cosmopolitismo / curiosidade cada percebe o outro como estranho, mas todos compartilham o mesmo ambiente de pertencimento, assim no percurso semântico da alienação / suspeita cada percebe o outro como insider, mas ninguém compartilha o mesmo ambiente de pertencimento (e portanto, todos compartilham o mesmo ambiente de não pertencimento). Por exemplo, se o percurso semântico de cosmopolitismo / curiosidade é típico daquelas "sociedades de migrantes", em que a coesão social é um resultado do fato de encontrar um terreno comum nas diferenças, o percurso semântico de estranhamento / suspeita é típico dessas "sociedades nacionais" onde a desintegração social produz como resultado o fato de encontrar diferenças no terreno comum.

Tal como no percurso semântico de exilio / invasão, também aqui a relação entre o sujeito dinâmico e o sujeito estático é antagonista, uma vez que em ambos 
os casos a intensidade da transição é ampliada. No entanto, o percurso semântico de exílio / invasão difere daquele de alienação / suspeita em relação à extensão da distância: no primeiro caso, os insider sentem que seu ambiente de pertencimento é ameaçado por estrangeiros que cruzam a fronteira vindo doutro lugar distante. No segundo caso, pelo contrário, os insiders sentem que seu ambiente de pertencimento é ameaçado por outros insiders.

\section{A retórica do pertencimento}

Os diagramas tensivos descritos acima contribuem para exibir não apenas uma pluralidade de percursos semânticos, mas também uma multiplicidade de operaçôes dinâmicas. Em outras palavras, os diagramas fornecem esquematizaçóes das formas em que diferentes tipos de discurso podem promover esta ou aquela transição entre regimes de pertencimento sugerindo uma substituição mais ou menos rápida de figuras de atravessamento.

A estratégia retórica de cosmopolitismo e curiosidade consistirá na elaboração de discursos que, gradualmente, substituíam as figuras de atravessamento caracterizadas por máxima intensidade de transição e mínima extensão de distancia com figuras de atravessamento caracterizadas por mínima intensidade de transição e máxima extensão de distância. Esta mudança vai resultar numa passagem de alienação e suspeita a cosmopolitismo e curiosidade.

De acordo com esta estratégia retórica, os indivíduos dum grupo serão mais e mais encorajados a considerar que outros indivíduos dentro do mesmo grupo são cada um equipado com características especiais, que os tornam todos diferentes uns dos outros em termos de, por exemplo, etnia, classe socioeconômica, orientação sexual, crenças religiosas, etc. Por meio de estratégias retóricas de cosmopolitismo e curiosidade, os membros dum determinado ambiente de pertencimento aprendem a perceber as diferenças entre eles mesmos e outras pessoas no mesmo ambiente, e assim deixam de perceber esse ambiente como um bloco monocromático e começam a colher nele algumas matizes. Ao mesmo tempo, por meio de estratégias retóricas de cosmopolitismo e curiosidade, os membros dum determinado ambiente de pertencimento vão aprender como reagir a essa variedade interna não com desconfiança, mas com curiosidade, não com agressividade antagônica, mas com hospitalidade cooperativa.

As naçóes multiculturais, como a Austrália e o Canadá, anualmente investem recursos substanciais na concepção e no desenvolvimento de programas para incentivar nos cidadãos a consciência e a valorização da diversidade sociocultural da populaçáo. O sucesso desses programas depende rigorosamente da medida em que eles são capazes de criar figuras persuasivas de cosmopolitismo e curiosidade, adequadas para substituir as de alienação e suspeita. Supérfluo acrescentá-lo, estes caros programas são, por vezes, menos eficazes do que textos ficcionais, como novelas, filmes, músicas, etc., que geram a mesma inversão de regime de pertencimento por meio do poder do seu discurso poético (Leone 2010b; Leone 2013). Graças a esses textos ficcionais, os indivíduos dum grupo, por vezes, começam a acreditar 
que qualquer outra pessoa no mesmo grupo é de fato uma fonte de surpresa sem fim, una fonte para guardar com entusiasmo. $\mathrm{O}$ resultado final do sucesso de estratégias retóricas de cosmopolitismo e curiosidade é a confiança multicultural.

Por outro lado, uma estratégia retórica oposta de estranhamento e suspeita consistirá na produção de discursos que mais ou menos gradualmente substituem figuras de atravessamento caracterizadas por mínima intensidade de transição e máxima extensão de distância com figuras de atravessamento caracterizadas por máxima intensidade de transição e mínima extensão de distância. Esta mudança vai resultar numa passagem de cosmopolitismo e curiosidade para alienação e suspeita.

Por exemplo, de acordo com esta estratégia retórica, os indivíduos dentro dum grupo serão cada vez mais encorajados a considerar os outros indivíduos no mesmo grupo como equipados exatamente com as mesmas características essenciais, que tornam sua origem étnica, sua classe socioeconômica, sua orientaçáo sexual, suas crenças religiosas, etc. completamente irrelevantes. Por meio de estratégias retóricas de alienação e suspeita, os membros dum determinado ambiente de pertencimento aprenderão a esquecer as diferenças entre eles mesmos e outras pessoas no mesmo ambiente. Eles deixarão de captar nuances neste ambiente e começarão a percebê-lo como um bloco monocromático. Ao mesmo tempo, por meio de estratégias retóricas de alienação e suspeita, os membros dum determinado ambiente de pertencimento aprenderão a reagir à esta ausência de variedade interna com desconfiança e agressividade antagônicas.

As teorias antropológicas que retratam os seres humanos como todos propensos ao mesmo egoísmo socioeconômico geralmente utilizam recursos simbólicos consideráveis na concepção e no desenvolvimento de ideias que visam incentivar os cidadáos a acreditar que todos eles deveriam estar cientes da monotonia incrível de motivação por trás do comportamento doutros indivíduos: cobiça, cobiça, e mais cobiça. $\mathrm{O}$ sucesso dessas ideias depende criticamente da medida em que elas sejam capazes de criar figuras persuasivas de estranhamento e suspeita capazes de substituir as de cosmopolitismo e curiosidade. Supérfluo acrescentá-lo, por vezes essas teorias antropológicas são menos eficazes do que, por exemplo, a propaganda política e econômica que gera a mesma inversão de regime de pertencimento por meio do poder do discurso dos mídia. Através destes meios de comunicação, os indivíduos dum grupo às vezes começam a acreditar que a conduta de qualquer outro indivíduo no mesmo grupo confirmam suas suspeitas. $\mathrm{O}$ resultado final do sucesso de estratégias retóricas de estranhamento e suspeita é a desconfiança monocultural.

Uma terceira estratégia retórica de aclimatação e tolerância consistirá na produção de discursos que mais ou menos gradualmente substituem figuras de atravessamento caracterizadas por intensidade de transição e extensão de distancia máximas com figuras de atravessamento caracterizadas por intensidade de transição e extensão de distância mínimas. Essa substituição vai resultar em uma passagem de 
exílio e invasão para aclimatação e tolerância.

Por exemplo, mesmo de acordo com essa estratégia retórica, os indivíduos dum grupo serão mais e mais incentivados a considerar que outros indivíduos no mesmo grupo todos têm exatamente as mesmas características essenciais, que tornam sua origem étnica, classe socioeconômica, orientação sexual, crenças religiosas, etc. completamente irrelevantes. Por meio de estratégias retóricas de aclimatação e tolerância, os membros dum determinado ambiente de pertencimento também vai aprender a esquecer as diferenças entre eles mesmos e outras pessoas no mesmo ambiente. Eles deixarão de captar nuances neste ambiente e começarão a percebê-lo como um bloco monocromático. Ao mesmo tempo, ao contrário das estratégias retóricas de alienação e de desconfiança, as de aclimatação e tolerância incentivam os membros dum determinado ambiente de pertencimento à confiança e ao comportamento cooperativo.

As políticas sociais de assimilação e integração normalmente utilizam consideráveis recursos simbólicos na elaboração e desenvolvimento de ideias que visam incentivar os cidadáos a acreditar na superação de suas peculiaridades socioculturais e no primado de seu terreno comum. $\mathrm{O}$ sucesso dessas ideias depende criticamente da medida em que elas são capazes de criar figuras persuasivas de aclimatação e tolerância, adequadas para substituir as de exilio e invasão. Será supérfluo dizer que, a vezes, essas políticas sociais são menos eficazes do que os processos demográficos que geram a mesma inversão de regime de pertencimento através do poder dos números: características socioculturais excepcionais tornam-se normais como resultado do aumento da sua significância estatística. Graças a estes processos demográficos, os indivíduos dum grupo por vezes começam a acreditar que todos os outros indivíduos no mesmo grupo compartilha o mesmo terreno comum e responde a esta convicção com a atitude em acorde com a qual "afinal de contas, somos todos iguais.” O resultado final do sucesso das estratégias retóricas de aclimatação e tolerância é a confiança monocultural.

Finalmente, uma quarta estratégia retórica de exílio e invasão consistirá na produção de discursos que mais ou menos gradualmente substituir figuras de atravessamento caracterizadas por intensidade de transição e extensão de distancia mínimas com figuras de atravessamento caracterizadas por intensidade de transição e extensão de distância máximas. Esta mudança vai resultar em uma passagem de aclimatação e tolerância a exilio e invasão.

De acordo com esta estratégia retórica, os indivíduos dum grupo serão incentivados a considerar cada vez mais que outros indivíduos no mesmo grupo ser cada um equipado com características únicas, que os tornam todos diferentes em termos de, por exemplo, etnia, classe socioeconómica, orientação sexual, crenças religiosas, etc. Por meio de estratégias retóricas de exílio e invasão, os membros dum determinado ambiente de pertencimento aprenderão a perceber as diferenças entre eles mesmos e outras pessoas no mesmo ambiente, e assim deixarão de perceber esse ambiente como um bloco monocromático e começarão a colher, nesse 
ambiente, algumas nuances. Ao mesmo tempo, por meio de estratégias retóricas de exílio e invasão, os membros dum determinado ambiente de pertencimento vai começar a reagir a esta variedade interna não com curiosidade, mas com desconfiança, não com hospitalidade cooperativa, mas com agressividade antagônica (Leo 2009b).

Os líderes políticos xenófobos costumam utilizar recursos simbólicos consideráveis na elaboração e no desenvolvimento de ideias destinadas a incentivar as pessoas a acreditar que todos eles deveriam conscientemente ter medo da diversidade sociocultural da população.

As semelhanças devem ser objeto de confiança, as diferenças de medo. $\mathrm{O}$ sucesso desses líderes depende criticamente da medida em que eles são capazes de criar figuras persuasivas de exílio e invasão, adequadas para substituir às de aclimatação e tolerância. Supérfluo acrescentá-lo, por vezes ideologias desse tipo são menos eficazes do que, por exemplo, programas de televisão que geram a mesma inversão do esquema de pertencimento através do poder do discurso dos mídia. Graças a esses textos mediáticos, os indivíduos dum grupo por vezes começam a acreditar que todos os outros indivíduos do mesmo grupo é de fato uma fonte de surpresa infinita a fugir com terror. O impacto cumulativo das estratégias retóricas de exílio e de alienação é a desconfiança multicultural.

\section{Conclusão: A axiologia do pertencimento}

Apesar do que a tipologia de percursos semânticos e estratégias retóricas de pertencimento até agora proposta for construída a partir duma perspectiva rigorosamente fenomenológica e semiótica e sem nenhuma intenção ideológica particular, esta tipologia implica claramente uma axiologia. Os percursos semânticos e as estratégias retóricas que se movem da desconfiança para a confiança social são percebidos como mais desejáveis d aqueles que se movem na direção oposta. Afinal, é difícil sustentar a ideia de que as sociedades em que a desconfiança é mais comum da confiança social sejam mais desejáveis, já que a natureza duma sociedade é, na verdade, baseada na cooperação.

Com relação ao movimento dos percursos semânticos e das estratégias retóricas de confiança monocultural aos de confiança multicultural, sua axiologia é mais ambígua. Alguns poderiam argumentar que uma sociedade em que os indivíduos são mutuamente conscientes e bem dispostos os uns em relação aas peculiaridades socioculturais dos outros, respondendo a elas com curiosidade, confiança e cooperação, é na verdade nada mais do que uma sociedade utópica, que nunca se tornará uma realidade. Eles poderiam argumentar que a confiança e a cooperação nas sociedades não decorrem da percepção curiosa das diferenças, mas a partir da consciência confortável das semelhanças. Todo o debate em torno da integração versus as políticas multiculturais poderia ser interpretada como um debate sobre as estratégias retóricas de aclimatação e tolerância versus aquelas de cosmopolitismo e curiosidade.

No entanto, se poderia também acreditam que as sociedades em que os 
sujeitos (sejam eles indivíduos ou grupos) podem ter um lugar em um ambiente social de pertencimento, sem sacrificar sua identidade, é mais desejável das sociedades em que o outsider pode encontrar um lugar só se começa a comportam-se como um insider. De fato, se aceitarmos a premissa de que as sociedades, exatamente como as línguas, são caracterizados pela infinita capacidade de diferenciação interna, então se deveria também reconhecer a capacidade das sociedades de recriar constantemente as diferenças entre insiders e outsiders que são temporariamente embotadas por meio de estratégias retóricas de aclimatação e tolerância (Leone 2009c). Afinal, é difícil sustentar a ideia de que as sociedades em que a diversidade cultural não é um obstáculo pela confiança e a cooperação social, mas ferramenta delas, são menos desejáveis, porque a própria natureza duma sociedade implica uma constante produção e reprodução de diferenças culturais.

No entanto, antes de tirar conclusóes precipitadas sobre quais regimes de pertencimento são os mais desejáveis para as sociedades atuais e futuras, os diagramas vazios acima descritos devem ser preenchidos com casos de estudos concretos. Espero fazê-lo através de estudos futuros, em que as mais comuns estratégias retóricas de pertencimento das sociedades contemporâneas serão descritas e analisadas em profundidade. 


\section{Referências Bibliográficas}

Allatson, P., McCormack, J., eds, 2008, Exile Cultures, Misplaced Identities, Amsterdam e New York, Rodopi.

Andrews, E., Maksimova, E., 2008, "Semiospheric Transitions: A Key to Modelling Translation”, em "Sign System Studies", vol. 36, n. 2, pp. 259-270.

Appiah, K.A., 2007, Cosmopolitanism: Ethics in a World of Strangers, New York, W.W. Norton \& co.

Attali, J., 2003, L'Homme nomade, Paris, Fayard.

Auer, P., Schmidt, J.E., eds, 2010, Language and Space: An International Handbook of Linguistic Variation, Berlin e New York, Walter de Gruyter.

Bail, C., 2008, "The Configuration of Symbolic Boundaries against Immigrants in Europe", "American Sociological Review", vol. 73, pp. 37-59.

Barnard, H., Wendrich, W., eds, 2008, The Archaeology of Mobility: Old World and New World Nomadism, Los Angeles, Cotsen Institute of Archaeology, University of California.

Beck, U., 2004, Der kosmopolitische Blick, oder, Krieg ist Frieden, Frankfurt, Suhrkamp.

Benhabib, S., 2008, Another Cosmopolitanism, Oxford, UK, Oxford University Press.

Benveniste, É., 1966, Problèmes de linguistique générale, I, Paris, Gallimard.

Benveniste, É., 1971, Problèmes de linguistique générale II, Paris, Gallimard.

Cabrera, L., 2010, The Practice of Global Citizenship, New York, Cambridge University Press.

Caillois, R., 1956, L'Incertitude qui vient des rêves, Paris, Gallimard.

Callari Galli, M., ed., 2007, Contemporary Nomadisms: Relations between Local Communities, Nation-States and Global Cultural Flows, Berlin e Zurich, Lit.

Carrera, H, a cura, 2010, Exils, Perpignan, Presses de l'Université de Perpignan.

Cavicchioli, S., 2002, I sensi, lo spazio, gli umori e altri saggi, Milano, Bompiani.

Cavicchioli, S., a cura, 1997, La spazialità: valori, strutture, testi, "Versus" [numero monografico], voll. 73/74.

Chung, R., Nootens, G., a cura, 2010, Le Cosmopolitisme: Enjeux et débats contemporains, Montréal, Presses de l’Université de Montréal. 
Coquet, J.-C., 2007, Phusis et logos: Une phénoménologie du langage, Saint Denis, Presses Universitaires de Vincennes.

Costa do Nascimento, E., 2008, Nomadismos contemporâneos: Um estudo sobre errantes trecheiros, San Paolo, Editora UNESP.

Crapanzano, V., 2003, Imaginative Horizons: An Essay in LiteraryPhilosophical Anthropology, Chicago, the University of Chicago Press.

De Genova, N., Peutz, N., eds, 2010, The Deportation Regime: Sovereignty, Space, and the Freedom of Movement, Durham, N.C., Duke University Press.

Delanty, G., 2009, The Cosmopolitan Imagination: The Renewal of Critical Social Theory, Cambridge, UK, Cambridge University Press.

Delanty, G., Inglis, D., eds, 2011, Cosmopolitanism: Critical Concepts in the Social Sciences, 4 voll., Londres e New York, Routledge.

Fontanille, J., Zilberberg, C., 1998, Tension et signification, Sprimont, Mardaga.

Forte, M.C., ed., 2010, Indigenous Cosmopolitan: Transnational and Transcultural Indigeneity in the Twenty-First Century, Frankfurt, Peter Lang.

Hammad, M., 2006, Lire l'espace, comprendre l'architecture: essais sémiotiques, Limoges, PULIM; Parigi, Geuthner.

Harvey, D., 2009, Cosmopolitanism and the Geographies of Freedom, New York, Columbia University Press.

Hernes, T., 2004, "Studying Composite Boundaries: A Framework of Analysis", in "Human Relations", vol. 57, pp. 9-29.

Hess-Lüttich, E.W.B., Müller, J.E., Van Zoest, eds, 1998, Signs and Space: An International Conference on the Semiotics of Space and Culture in Amsterdam, Tübingen: G. Narr.

Holton, R.J., 2009, Cosmopolitanisms: New Thinking and New Directions, Basingstoke, Palgrave Macmillan.

Jaworski, A., Thurlow, C., eds, 2010, Semiotic Landscapes: Language, Image, Space, Londres, Continuum international publishing group.

Jones, R., 2009, “Categories, Borders and Boundaries", em "Progress in Human Geography”, vol. 33, n. 2, pp. 174-189.

Kendall, G., Woodward, I., Skrbis, Z., eds, 2009, The Sociology of Cosmopolitanism: Globalization, Identity, Culture and Government, Basingstoke: Palgrave Macmillan.

Leder, S., Streck, B., eds, 2005, Shifts and Drifts in Nomad-Sedentary Relations, Wiesbaden, L. Reichert.

Leone, M., 2003, “Gli impermeabili-Soglie della sensibilità”, em “Golem indispensabile”, fevrero, accessível no sito www.golemindispensabile.it/ 
index.php?_idnodo=7236\&_idfrm=61 (último download o 3 de novembro de 2012).

Leone, M., 2006a, "Le Concept de frontière de Lotman à Perec", em "Le Conférences françaises à l'Université du Luxembourg”, accessível no sito www.uni.lu/recherche/flshase/laboratoire_en_litterature_et_linguistique_francaises/les_conferences_francaises/textes_des_conferences (último download o 3 de novembro de 2012).

Leone, M., 2006b, "Ospitalità permanente: Intorno alla semiotica dello spazio sacro", em "Carte semiotiche”, voll. 9-10, pp. 117-131.

Leone, M., 2007, "Appunti per una semiotica della frontiera", em "Solima"; accessível no sito www.solima.media.unisi.it (último download o 3 de novembro de 2012).

Leone, M., 2009b, "Sustainable Religions in Contemporary Cities: A Semiotic Approach", "International Journal of Environmental, Cultural, Economic, and Social Sustainability”, vol. 5, n. 3, pp. 47-59.

Leone, M., 2009c, "The Paradox of Shibboleth - Immunitas and Communitas in Language and Religion”, em G. Gallo, ed., Natura umana e linguaggio, "RIFL - Rivista italiana di filosofia del linguaggio" [número monográfico], vol. 1, pp. 131-157; accessível no sito www.rifl. unical.it/news/base.php?subaction=showfull\&id=1252453101 (último download o 3 de novembro de 2012).

Leone, M., 2010a, "Invisible Frontiers in Contemporary Cities An Ethno-Semiotic Approach", em "The International Journal of Interdisciplinary Social Sciences”, vol. 4, n. 11, pp. 59-74.

Leone, M., 2010b, "Legal Controversies about the Establishment of New Places of Worship in Multicultural Cities: a Semiogeographic Analysis", em A. Wagner, J. Broekman, eds, Prospects in legal semiotics, Berlino e New York, Springer, pp. 217-237.

Leone, M. 2010c. "On my Accent - Signs of Belonging in PresentDay Multicultural Societies", in M. Leone, ed., Analysis of Cultures - Cultures of Analysis, "Lexia", nova serie [número monográfico], voll. 5-6, pp. 415-450.

Leone, M., 2011a. "Rituals and Routines", em "Chinese Semiotic Studies", vol. 5, n. 1 (June 2011), pp. 107-120.

Leone, M., 2011b. "Alcune recenti pubblicazioni di semiotica urbana", recensione-saggio, in Immaginario/Imaginary, "Lexia" nova serie [numero monográfico], voll. 7-8.

Leone, M. 2012. "Hearing and Belonging: On Sounds, Faiths, and Laws", em V.K. Bhatia, A. Wagner, C. Haffner, L. Miller, eds, Perspectives in Legal Communication, [Law, Language, and Communication Series] Farnham (Surrey), Ashgate, pp. 183-198 
Leone, M., 2013. A. "Citizens of a Lesser God: Religious Minorities and the Legal Discourse of Multi-Cultural Democracies", em B. Wojciechowski, P.W. Juchacz, e K. Cern, eds. 2013. Legal Rules, Moral Norms and Democratic Principles [series Dia-Logos]. Frankfurt am Main: Peter Lang Publishing Group, pp. 163-81.

Leone, M., ed., 2009a, The City as Text: Urban Writing and Re-Writing, "Lexia" nova serie [número monográfico], voll. 1-2.

Lotman, J.M., 2000, Universe of the Mind: A Semiotic Theory of Culture (1990), traduzido do russo por A. Shukman, Londres, Tauris.

Lussault, M., 2007, L'Homme spatial: la construction sociale de l'espace humain, Paris, Seuil.

Manetti, G., 1998, La teoria dell'enunciazione: L'origine del concetto e alcuni più recenti sviluppi, Siena, Protagon.

Manetti, G., 2008, L'enunciazione: Dalla svolta comunicativa ai nuovi media, Milano, Mondadori Università.

Marcos, I., ed., 2007, Dynamiques de la ville: Essais de sémiotique de l'espace, Paris, l'Harmattan.

Marrone, G., ed., 2010, Palermo: ipotesi di semiotica urbana, Roma, Carocci.

Mau, S., 2010, Social Transnationalism: Lifeworlds beyond the NationState, Londres, Routledge.

Mohr, R., 2009, “'Allontanarsi dalla linea gialla': Distance and Access to Urban Semiosis", in M. Leone, a cura, Actants, Actors, Agents: The Meaning of Action and the Action of Meaning: From Theories to Territories, "Lexia" nova serie [número monográfico], voll. 3-4.

Ó hAodha, M., ed., 2007, The Nomadic Subject: Postcolonial Identities on the Margins, Newcastle, UK, Cambridge Scholars Pub.

Ono, A., 2007, La Notion d'énonciation chez Émile Benveniste, Limoges, Lambert-Lucas.

Ouditt, S., ed., 2002, Displaced Persons: Conditions of Exile in European Culture, Aldershot, UK; Burlington, VT, Ashgate.

Sassen, S., ed., 2007, Deciphering the Global: Its Scales, Spaces and Subjects, New York, Routledge.

Scholz, F., 1995, Nomadismus: Theorie und Wandel einer sozio-ökologischen Kulturweise, Stuttgard, F. Steiner

Schönle, A., ed., 2006, Lotman and Cultural Studies: Encounters and Extensions, Madison, Wis., University of Wisconsin Press.

Tilly, C., 2004, "Social Boundary Mechanisms", em "Philosophy of the Social Sciences”, vol. 34, pp. 211-236.

Velázquez, T., a cura, 2009, Fronteras, De Signis [número monográfico], 
vol. 13 .

Zilberberg, C., 2006, Éléments de grammaire tensive, Limoges, PULIM. 